\title{
2D Pong Game using DirectX
}

\author{
Apoorva A. Patil, Abhishek S. Hegde, Akshay E. Kulkarni
}

\begin{abstract}
This paper describes about designing and developing a tennis based two dimensional pong game using Computer Graphics concepts and technologies like DirectX on Microsoft Visual Studio Platform. It is a player vs. player game with some rules.To implement this game, the project involves software programming. The game logic is written in visual $C++$ which is the advanced version of $C$ programming language.
\end{abstract}

Keywords--- Direct X, Pong, Paddle, Ball, Microsoft Visual Studio.

\section{INTRODUCTION}

$\mathrm{P}$ ONG is a two player two dimensional game that replicates the table tennis sport. In this game one player controls paddle on one side by moving it vertically and can compete against second player controlling a second paddle on the opposing side. Using the paddles players will try to hit the ball back in opposite direction, points will be earned when player fails to return the ball to the other player. The goal for each player is to score ten points before the opponent. For this project, basic knowledge of the Microsoft Visual Studio IDE and new graphics technology like Directx is required. And enough knowledge of an object-oriented programming language like $\mathrm{VC}++$ is also essential. Using the suitable information of the above tools with respect to game development and step by step approach, this game can be designed and built.

\section{LITERATURE SURVEY}

Pong was one of the earliest popular video games whose versions where built. This game was originally made and released in 1972 by Atari Incorporated (Atari). Allan Alcorn, creator of Pong did it as a training exercise assigned to him by Atari co-founder Nolan Bushnell. Bushnell proposed an idea about creating an electronic ping-pong based game. Pong game became a huge success commercially which in turn helped to establish the video game industry.

In 1975, home edition of Pong video game machine was released by Atari and thousands of units were sold. After its release, several other companies started producing games which had pong's gameplay both electronically and digitally. Today, the Pong game is truly considered as one of the very few revolutionary games which provided a much needed kickstart to the video games market and helped in producing high

Apoorva A. Patil, UG student, Computer Science Department, SDMCET, Dharwad, Karnataka.E-mail:a.a.patil217@gmail.com

Abhishek S. Hegde, UG student, Computer Science Department, SDMCET, Dharwad, Karnataka.E-mail:abhi.s.hegde@gmail.com

Akshay E. Kulkarni, UG student, Computer Science Department, SDMCET, Dharwad, Karnataka.E-mail:akshayekulkarni95@gmail.com DOI:10.9756/BIJSESC.8274 revenues.

\section{GAME RULES \& PROCEDURES}

A. Rules of the Game

1) Start of game: The application program is run and based upon the player side it is played, it can be of individual play also.

2) Serve: When the players strike the ball with their own paddle first and send it back to the opposite side then it is called a serve.

3) Volley: Volley is where the opposite player performs the same serve and sends the ball back to opposite side.

4) End of volley: Volley comes to an end when the ball travels past the player's paddle and touches the wall.

5) End of Game: Game ends when one player scores the winning points, which is a fixed score before the other player or the game ends when either of the player quits the game.

\section{B. Game Procedure}

Players must strike the ball with their paddle and pass it on to the other player. Scores are scored when the opposite player misses the ball and the ball touches the wall behind that player's paddle. As the game proceeds the speed of the ball increases. Based on the point of stike of the ball and the paddle the spin of the ball is determined. Spinning of the ball gives an advantage to the hitter and he has a better chance of scoring if the spin is successful.

\section{DESIGN \& GAME IMPLEMENTATION}

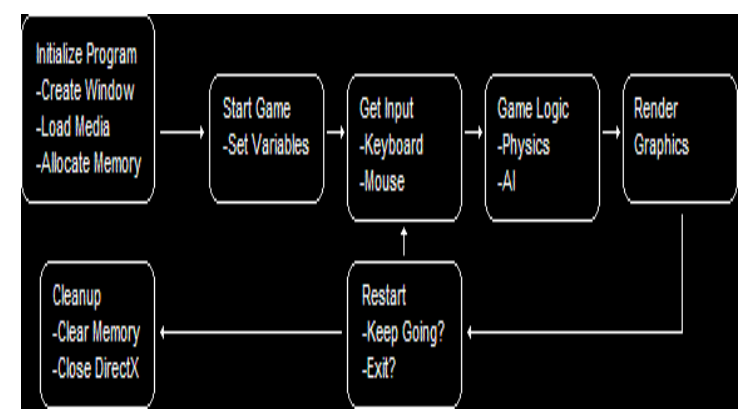

Figure 1: Sequence of Basic Computer Game

Below are the different phases invloved in the building and implementation of this game;

\section{A. Phase 1: Initialize the Program}

In this phase development of the game starts with the initialization of the program. Eg. A window is created to display, directX graphics are loaded, models and media are used, allocating the memory and so on.

\section{B. Phase 2: Start the Game}

This part basically deals with the actual setting of the game 
to be played. Eg. setting the location of paddles.

\section{Phase 3: Get Input from the Players}

Here in this phase, from the input device used by the players all the required information is taken.

\section{Phase 4: Run the Game Logic}

In this phase the actual logic is being run which deals with in-game functionalities. Eg. The speed of the paddles, the collision of the ball with paddle, the speed of the ball etc.

\section{E. Phase 5: Render Graphics}

This is the phase where the DirectX graphics comes into the picture. All the required graphics are called from the library and processed and finally rendered.

\section{F. Phase 6: Restart}

Here if the player intends to keep playing then the control goes back to phase 3, else it exits.

\section{G. Phase 7: Cleanup}

In this final phase as the program is ending all activites are stopped and cleared. DirectX shuts down the graphic interfaces. And resources are released.

\section{SYSTEM REQUIREMENT SPECIFICATION}

\section{A. Hardware Requirements}
1) 2 GB RAM (4GB is recommended)
2) 3 GB of Hard Drive Space
3) $1.6 \mathrm{GHz}$ or faster processor
4) Built in GPU of 1 GB or more

\section{B. Software Requirements}

1) Microsoft Visual Studio (community edition is used here)

2) DirectX 11 SDK

3) $\mathrm{VC}++$ language is used for programming.

VI. PlAYER-GAME MODEL

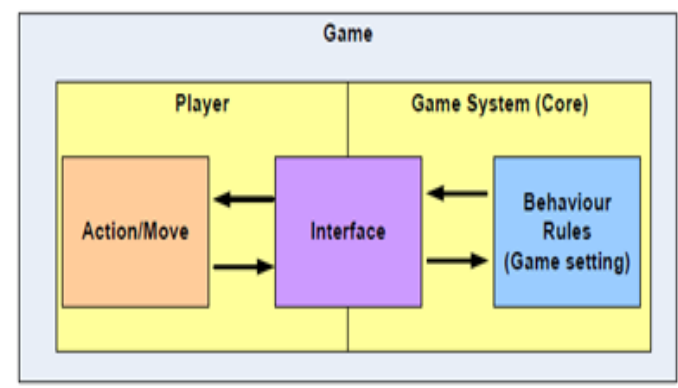

Figure 2: Block Representation of player-game model

The above is the player-game model that this game is based on. It contains two parts; one is the player related part and other one is system related core part. There are totally three blocks involved here. First one is the action/move block which is all about the player's moves and the action performed. Next is about the behaviour rules and game settings, this is where the core game related settings, rules and functions are written. Then there is interface block which works as an intermediate between the the two blocks i.e player side as well as system side. This is the overall player-game model.

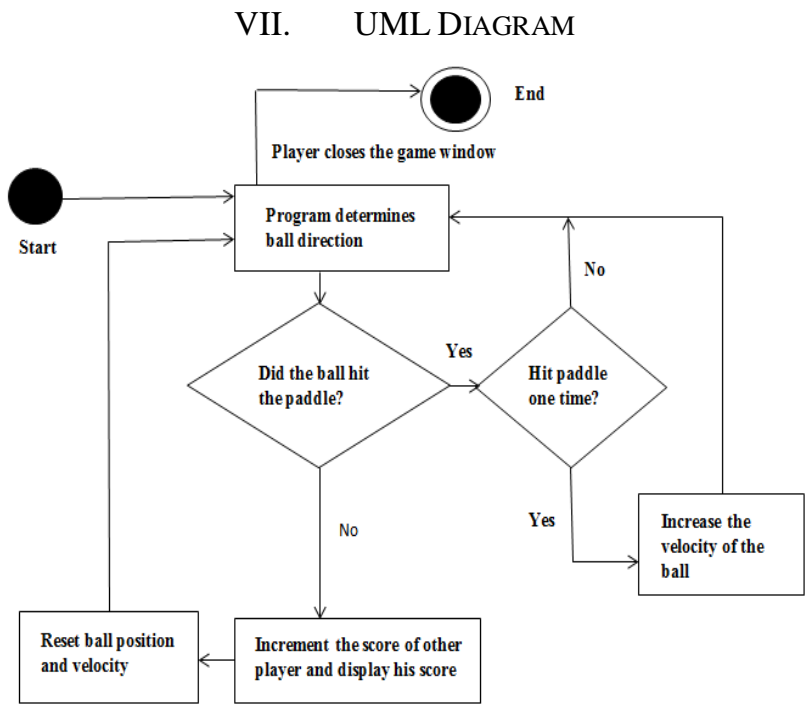

Figure 3: UML Representation

\section{GRAPHICAL USER INTERFACE}

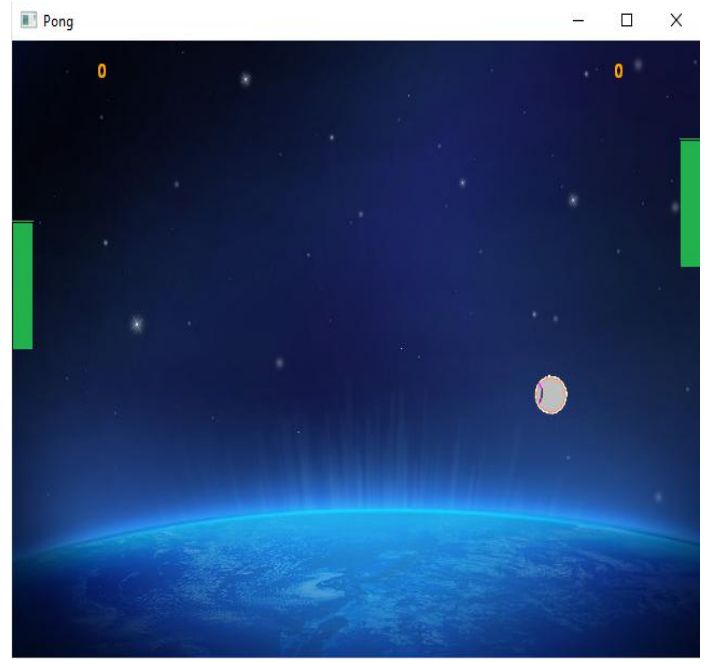

Figure 4: Pong Gameplay

\section{RELEVANCE}

1) The game built is a computer based tennis sport game.

2) Two players can play this game with separate paddles on either side with them having the control of paddles using the keyboard.

3) This project is done with the help of computer graphics concepts.

4) This helps us in developing a game using $\mathrm{C}++$ concepts and DirectX library.

\section{CONCLUSIONS \& FUtURE ENHANCEMENT}

We have efficiently used all the tools and technologies (Directx, Visual Studio) in this game that has been created in this project. There still enough scope for future enhancements like; addition of sounds, options in menu, more interactive and 
immersive gameplay to name a few.

\section{ACKNOWLEDGMENT}

We wish to express our sincere thanks to our department, Computer Science and Engineering and the head of our department Prof. S.M. Joshi for supporting us to complete this project successfully. We are grateful to our project guide Prof. Govind Negalur for helping, supporting and being with us in facing the hurdles during this project work.

\section{REFERENCES}

[1] C. Kelly, "Programming 2D games", CRC press, 2012.

[2] F.D. Luna, "Introduction to 3D game programming with DirectX 11", Mercury learning and information, 2012

[3] R. Lafore, "Object-Oriented Programming in C++", Sams Publishing, 2001.

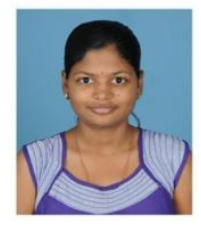

Apoorva A. Patil, currently pursuing final year B.E. in

SDM College of Engineering and Technology, Dharwad,

Karnataka.

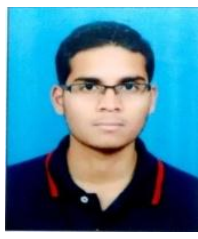

Abhishek S. Hegde, currently pursuing final year B.E. in SDM College of Engineering and Technology, Dharwad,

Karnataka.

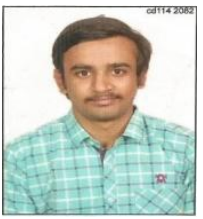

Akshay E. Kulkarni, currently pursuing final year B.E. in SDM College of Engineering and Technology, Dharwad,

Karnataka 